\title{
New and ancient trace makers
}

Stefan Bengtson ${ }^{1,2}$ and Birger Rasmussen ${ }^{3}$

Giant protists at nearly $800 \mathrm{~m}$ depth off the Bahamas have set a ball in motion that will force a reevaluation of putative animal traces in the early fossil record. Matz et al., in Current Biology (1), report up to $50 \mathrm{~cm}$ long traces made by globular protists actively moving, apparently rolling, on the sea floor. This discovery may remove the obligatory animal stamp from a number of Neoproterozoic trace fossils and provide a fresh view on controversially old Paleoproterozoic traces.

Trace fossils are a prominent source of information about ecological interactions and animal behavior. Unlike body fossils, they can generally be trusted to reflect the direct conditions of the place where they are found. They have not been transported or redeposited in the way that body fossils commonly have. Also, traces are easily preserved, since they are formed in sediment or rock.

Yet in one important respect they fail us. The sedimentological conditions for trace fossil preservation are different from those conducive to preserving most body fossils; in fact, trace-producing activities are usually detrimental to the preservation of body fossils. Hence the bodies of the trace makers are rarely found with the traces, and hence the maker typically remains unknown. The international commission that regulates zoological nomenclature indeed has 
endorsed a system of Linnean binomia for traces that is decoupled from the identity of the trace maker.

Knowing the trace maker is thus at best difficult, even in the Phanerozoic, where body fossils abound. A few animals may leave unique and recognizable footprints, but most trace fossil "taxa" can be produced by several organisms that may not be closely related. Trace fossils reflect behavior, not biological affinity.

The sudden appearance of animal fossils at the beginning of the Cambrian period, now dated to 542 million years ago, has long been recognized as an ecological revolution involving the rampant radiation of multicellular taxa, not the artifact of preservation that was surmised by the great scientists of former centuries, such as Charles Darwin and Charles Doolittle Walcott. Trace fossils played a great role for this insight. They show a rapid evolution of behavior at this time, thereby demonstrating that the appearance of a diverse fauna was a real biological event, not merely the effect of improved conditions for fossilization. The famous soft-bodied impressions of the Ediacara "fauna" that precede the Cambrian have turned out to be problematic in terms of their animal affinities, but co-occurring traces seem to provide strong independent evidence that among the exotic Ediacarans there crawled true bilaterian animals (2).

This is probably an oversimplification, however. Some alleged traces have recently turned out to be body fossils of what has been interpreted as giant 
protists resembling modern xenophyophores (3). Other, simpler traces, might as easily be produced by any animal - including simple ones without a hydrostatic skeleton or bilateral symmetry - that progressed by gliding along its self-made mucus tract with the help of cilia (4). Trace fossils thus seemed to have increasingly less to contribute about the early evolution of animals. This is not to say that bilaterian animals or their traces did not exist during the Ediacaran Period. There are believable body fossils of a mollusk-like organism, Kimberella. Interestingly, the most convincing piece of evidence for its animal nature is its frequent association with feeding traces apparently made by radulas, the toothed tongues many mollusks use to scrape up their food (5).

If Ediacaran trace-like fossils have too readily been interpreted as the products of advanced bilaterian animals, the inverse is true about older occurrences. Because of the almost universal consensus that megascopic traces of motile organisms implicate animals, i.e. metazoans, evidence of older traces has been seen as spurious. Accepting them as traces, given an underlying assumption that they must have been made by animals, would clash with the general absence of animal body fossils before the Ediacaran, and this perceived anomaly has influenced their interpretation. Thus reports of motile multicellularity in the early rock record (e.g., 6, 7) have met with one of two responses: The rocks have been misdated, or the fossils have been misinterpreted (e.g., 8, 9). This is akin to a paleontological version of the Heisenberg uncertainty principle. 
Healthy skepticism is of course in place with regard to such often obscure structures as traces of simple organisms. The perceived anomaly only exists, however, under the assumption that trace fossils were always made by multicellular animals. Are there alternatives? Although unicellular organisms are commonly motile, they are generally too small to leave megascopic traces. Even those unicellulars that occasionally aggregate into "slugs", like slime molds, are not known to leave durable traces. The exceptional protists that attain the large size of multicellulars by having a syncytial (multinucleated) organization and/or incorporate inert material in their cytoplasm tend to be sessile, immobile.

Matz et al. (1) may now have resolved the anomaly by demonstrating that a common type of trace fossil need not have been made by animals at all. They observed large balls, up to $3 \mathrm{~cm}$ in diameter, slowly rolling(?) in different directions on the ocean floor and leaving behind a sinuous groove bordered by two low lateral ridges. Near a ball there was normally a central ridge between the lateral ones. The balls turned out to be giant testate protist, Gromia sphaerica, previously known from the Arabian Sea. The traces look like regular animal trace fossils, but Matz et al. also note that they are quite similar to the almost two billion-year-old Myxomitodes.

Myxomitodes was interpreted as traces formed by multicellular or syncytial organisms gliding along a mucus band, but since they were more than three times older than the earliest known animal, they were not likely to be animals 
(10). The affinities of this mysterious creature remain unknown, but the discovery of Gromia traces provides a real-life example of the kind of nonanimal megascopic motile eukaryote that was previously only hypothesized. Similarity is not identity, however. While both Gromia and the Myxomitodes trail maker move across the sediment surface in short forays rather than burrow, the differences are still considerable. In Myxomitodes we see evidence of shape change and copious mucus production that appear unlikely for a test-encased organism like Gromia.

Be that as it may, the real significance of the Gromia traces lies not in their resemblance to Myxomitodes but in the direct demonstration that large traces need not have been made by animals. With that interpretive restraint gone, the time may have come for a more general acceptance of the possibility that the long Proterozoic Eon saw more and larger organisms moving on the sea floor than is currently recognized. The long-standing question of how and why large, multicellular organisms started to emerge from the placid microbial biosphere may then be viewed over a wider temporal, environmental and taxonomic spectrum than the current focus on the Cambrian explosion tends to favor.

${ }^{1}$ Department of Palaeozoology, Swedish Museum of Natural History, Box 50007, SE-104 05 Stockholm, Sweden

${ }^{2}$ Nordic Center for Earth Evolution (NordCEE), Odense-CopenhagenStockholm 
${ }^{3}$ Department of Applied Geology, Curtin University of Technology, GPO Box U1987, Perth, WA 6845, Australia

[Figure caption] Reconstruction of Gromia making traces on the sea floor (left; illustration Javier Herbozo), and the 1.8-2 billion year old trace fossil Myxomitodes (right; from reference (10))

1. M. V. Matz, T. M. Frank, N. J. Marshall, E. A. Widder, J. Sönke, Current Biology in press (2008).

2. T. P. Crimes, in The Palaeobiology of Trace Fossils S. K. Donovan, Ed. (Johns Hopkins UP, Baltimore, Maryland, 1994) pp. 105-133.

3. A. Seilacher, D. Grazhdankin, A. Legouta, Paleontological Research 7, 4354 (2003).

4. A. G. Collins, J. H. Lipps, J. W. Valentine, Paleobiology 26, 47-55 (2000).

5. A. Seilacher, L. Buatois, M. G. Mángano, Palaeogeography, Palaeoclimatology, Palaeoecology 227, 323-356 (2005).

6. A. Seilacher, P. K. Bose, F. Pflüger, Science 282, 80-83 (1998).

7. B. Rasmussen, S. Bengtson, I. R. Fletcher, N. McNaughton, Science 296, 1112-1115 (2002).

8. R. J. Azmi, Science 282, 627 (1998).

9. S. Conway Morris, Science 298, 57-58 (2002).

10. S. Bengtson, B. Rasmussen, B. Krapež, Paleobiology 33, 351-381 (2007). 